Article

\title{
Economic Benefit Evaluation System of Green Building Energy Saving Building Technology Based on Entropy Weight Method
}

\author{
Hanguang Lu ${ }^{1}$, Xiaojie Sheng ${ }^{1, *}$ and Fei Du ${ }^{2}$ \\ 1 School of Civil Engineering, Jinjiang College, Sichuan University, Meishan 620800, China; \\ olsi5190035laoxin@163.com \\ 2 China Construction Third Engineering Bureau Group Co., Ltd., Wuhan 430070, China; \\ e6529113puxun6180@163.com \\ * Correspondence: 201600150088@mail.sdu.edu.cn
}

Citation: Lu, H.; Sheng, X.; Du, F. Economic Benefit Evaluation System of Green Building Energy Saving Building Technology Based on Entropy Weight Method. Processes 2022, 10, 382. https://doi.org/ $10.3390 /$ pr10020382

Academic Editors: Weiping Zhang and Akbar Maleki

Received: 27 December 2021

Accepted: 3 February 2022

Published: 17 February 2022

Publisher's Note: MDPI stays neutral with regard to jurisdictional claims in published maps and institutional affiliations.

Copyright: (C) 2022 by the authors. Licensee MDPI, Basel, Switzerland. This article is an open access article distributed under the terms and conditions of the Creative Commons Attribution (CC BY) license (https:// creativecommons.org/licenses/by/ $4.0 /)$.

\begin{abstract}
The development of the construction industry has brought great convenience to people's lives, but the problems of resource shortages and energy consumption are becoming more and more serious. In order to solve the problem of resource shortages and energy consumption, this paper puts forward an evaluation system of technical and economic benefits of green building energy conservation based on the analytic hierarchy process and entropy weight method. In view of the correlation between building technology and economic benefits, this paper puts forward the economic benefit evaluation system of green building energy-saving technology combined with analytic hierarchy process and entropy weight methods, determines 6 first-class evaluation indexes and 20 s-class evaluation indexes, and takes the dynamic incremental investment payback period and incremental economic benefit ratio as the evaluation indexes, and finally obtains the economic benefit score and star value of green building. Combined with the actual situation of a middle school project, the incremental economic benefits of the four green technologies in energy conservation and resource utilization indicators are 44,256.75 yuan, 1,015,924.2 yuan, 255,490 yuan and $32,871.57$ yuan, respectively. The total incremental economic effect and unit incremental effect of the six evaluation indicators are 1,472,113.3 yuan and 1501.99 yuan $/ \mathrm{m}^{2}$ respectively. The economic effect of energy-saving and renewable resource utilization technology is the largest. The total score of the project is 0.404902 and it has three stars. Compared with traditional building technology, the application of green building technology and related facilities and equipment proposed in this paper can greatly reduce the consumption of building resources, so as to achieve the purpose of energy conservation and emissions reduction. This method combines objective evaluation with subjective evaluation, complements fair objective evaluation and expert evaluation, makes the best use of all basic information, and ensures the scientific effectiveness of the comprehensive evaluation model.
\end{abstract}

Keywords: analytic hierarchy process; entropy weight method; green energy saving technology; economic benefits; incremental effect

\section{Introduction}

With the rapid development of the social economy and the acceleration of urbanization, a series of problems such as ecological deterioration, environmental pollution and resource depletion are becoming more and more serious (Sim and Putuhena, 2015) [1]. Under the influence of the sustainable development strategy of the global economy, the construction industry, which has the worst pollution, has also put forward the term "green building". Green building has the characteristics of zero pollution emission, safe construction environment, scientific and reasonable energy-saving measures, efficient resource utilization rate and scientific regional planning (Ekwe and Abam, 2015) [2]. Its minimum resources and energy consumption, to achieve efficient use of space, to achieve the harmonious coexistence of human and nature. According to the green standard GB/t50378-2014, green 
building technology is divided into six categories, which are land saving and outdoor environment technology, energy-saving and energy utilization technology, water-saving and water resource utilization technology, indoor environment and quality control technology, and application management technology (Alimohammadi et al., 2015) [3]. Energy-saving technology is very important, and its weight proportion in each rating index is relatively high, which is embodied in the energy-saving technology of the green building envelope, energy-saving technology of air conditioning in green building, lighting and electrical energy-saving technology of green building, and renewable new energy utilization technology of green building (Ali et al., 2019) [4]. However, at present, the development of green building in China is relatively slow and immature, and there is little research on its economic benefit evaluation. To sum up, this paper puts forward a green building cost increment model, and combines AHP and entropy weight method to determine the combined weight to evaluate the economic effect.

In this study, a green building economic effect evaluation model based on AHP and entropy weight method is proposed. According to the previous research results, 6 first-level evaluation indexes and 20 s-level evaluation indexes are determined, and the calculation formula of the incremental effect of incremental cost is determined. Two evaluation indexes, dynamic incremental payback period and incremental economic effect ratio, are introduced to combine the subjective weight obtained by AHP. The objective weight obtained by the weight sum entropy weight method and the combined weight are solved. The 20 evaluation indexes based on green technology were quantitatively processed. Finally, the economic effect score was calculated and the score grade was determined.

In this paper, we use the entropy method to evaluate the economic efficiency of buildings. This method combines objective evaluation with subjective evaluation, which complement each other with fair and objective evaluation and expert evaluation, maximize the use of all basic information and ensure the scientific effectiveness of the comprehensive evaluation model. At the same time, the reference standard of the evaluation model is the current green building evaluation standard and star rating standard.

This study consists of four parts. The second part mainly introduces the current situation and challenges of green building economic effect evaluation, and introduces the application of the entropy weight method in many fields. The second part describes the analytic hierarchy process (AHP) and entropy weight algorithm, and introduces the economic effect model based on the combination of the two algorithms. The third part verifies the feasibility of the model and its application in the actual green building project through an example. The fourth part summarizes the experimental results, points out the shortcomings of this study, and points out the direction of further research.

\section{Related Work}

Green building energy-saving technology and related economic evaluation systems have become a hot topic for experts and scholars in related fields. In order to optimize the EDM process parameters in $\mathrm{Al}-18 \% \mathrm{SiCp}$ metal composites, Bhuyan et al. proposed the method of combining entropy weight method with the VIKOR method to optimize the parameters in the EDM process. VIKOR is a compromise multi-criteria decision-making method, which requires certain requirements for criteria and criteria values. In MCDM, it is not uncommon to meet VIKOR's demand for a multi-standard. The entropy weight method was used to determine the single weight of each response and the VIKOR method was used to optimize the multi-objective response. The conformational experiments show that the proposed method is very effective (Bhuyan and Routara, 2016) [5]. Taking Yuzhong Peninsula as an example, Batyrshin and other scholars put forward a fuzzy evaluation method of urban renewal decision-making based on the entropy weight method. Nine evaluation indexes such as social welfare, public facilities and ecological environment are set up, and a fuzzy matrix is constructed based on expert evaluation results. The evaluation results of different regions show that the evaluation results of zones $\mathrm{D}, \mathrm{E}$ and $\mathrm{H}$ are between 2 and 3, indicating that they are suitable for regeneration. Zone $\mathrm{H}$ is the 
key supporting object of economic development and planning, while zone E still has room for improvement in terms of buildings, facilities and spatial pattern (Zhou and Zhou, 2015) [6]. Ji and their team proposed a risk assessment method for Xiangxihe hydropower station, which integrated fuzzy entropy weight multi-criteria decision-making. Combining three methods of fuzzy set theory, the entropy weight method and multi-criteria decision-making method, the results show that the method avoids the subjective influence of weight, and can quantify the uncertainty of fuzzy concentration more objectively, and evaluate the multi-criteria decision-making problem more objectively Objective to solve the complex multi-index evaluation problem under the condition of sex (Ji et al., 2015) [7]. Taking a project in Peru as an example, Delgado et al. proposed an environmental conflict analysis method based on grey clustering and the entropy weight method. The qualitative information quantification of the grey clustering method and the identification divergence criterion of entropy weight method was integrated. The experimental results show that the new comprehensive evaluation method can effectively avoid the conflict between mining and environmental pollution, and is conducive to the sustainable development of energy (Delgado and Romero, 2016) [8]. In view of the rapid increase in the number of minimalist art and convenience stores, Kritsanwonghong et al. proposed a green building technology evaluation method for effective energy utilization. The evaluation index is the primary energy saving rate. The results show that the micro cogeneration system driven by a natural gas engine can meet the energy demand of convenience stores. At the same time, the efficiency of the micro cogeneration system is higher, and the PES value can be increased by $45 \%$ (Kritsanawonghong et al., 2014) [9].

In order to study the performance of the Bangkok Wanbao commuter service, Lertpocasambut and his team proposed a SketchUp-based green building technology for public toilet conceptual design. The results show that this kind of service can save fuel and toll, thus reducing travel costs (Lertpocasombut et al., 2016) [10]. In order to explore a method to ensure the reuse of ammonia nitrogen in coke oven wastewater, Kumar and his team carried out model simulation and economic evaluation research on an advanced membrane integrated mixed treatment process. The established model can better predict the production performance of crops, with low relative error and high overall correlation coefficient $\mathrm{Ku}$ mar et al., 2015) [11]. Bastardie et al. discussed the impact of population productivity and mixed change on sustainable fisheries and economic feasibility. By simulating the environment of different management, individual vessel decision-making, population growth and mixed scenarios, the results showed that when efforts were made to redistribute land-based sources, the existing management mechanisms could not correct the potentially harmful effects on COD fisheries, and the total profits would be less (Bastardie et al., 2016) [12]. Verhaeghe et al. proposed a Markov health economic assessment model for obesity and overweight, which became an important risk to human health. Reducing BMI can improve health status and reduce economic costs (Verhaeghe et al., 2016) [13]. In order to study the impact of income tax and property tax on property assets, Liapis and his team proposed fair value accounting and deferred income tax standards. The results show that the existence of the Laffe economic effect in real estate fully reveals the fair value of assets. This study provides a practical tool for decision-makers trying to define property tax macroeconomic policies, and can also be used as an evaluation model for individual investors (Liapis and Politis, 2018) [14]. Jara et al. considered the limitations of potential reform on income distribution in the current micro-simulation technology research, introduced the tax preference micro-simulation model Euromod, and proposed policy evaluation under the premise of subjective life satisfaction and equal income. The results show that the effect of potential reform is greatly different due to the welfare concept used in the evaluation (Jara and Schokkaert, 2017) [15].

At present, research shows that the entropy weight method has been used in many fields, such as economy, energy and so on, and has made a lot of breakthrough progress and achievements. However, there are still some deficiencies in the evaluation of the energy-saving economic effect of green buildings. This paper proposes a comprehensive 
evaluation method of green building technology by using the entropy weight method, which makes the evaluation results more stable and accurate.

\section{Economic Effect Evaluation Model of Green Energy-Saving Building Based on Entropy Weight Method \\ 3.1. Incremental Cost Effect of Green Energy Saving Building Technology}

At present, green building energy-saving technology has become a stumbling block in the development of the green energy-saving industry. In this paper, two concepts of incremental cost and incremental effect are introduced to analyze the economic effect of green building. The incremental cost ignores the cost of early decision-making consultation, and only considers the increased cost of energy-saving technology and advanced equipment. The calculation expression of the incremental cost of green building energy conservation is as follows (1).

$$
\Delta C=C_{1}-C_{0}
$$

In Formula (1), $C_{1}$ and $C_{0}$ represent the incremental cost after using green energysaving technology and the benchmark technology cost conforming to the local minimum mandatory implementation, respectively. Combined with previous research experience, 18 green building projects with a star logo have been obtained as the basis for incremental cost calculation. The data of average market research cost and average declaration cost of different star buildings show that the gap between average market research cost and average declaration cost of one-star green building is the largest, the former is almost $45 \%$ of the latter, while the two-star building and three-star building have the largest gap The average market research cost of construction accounts for $83 \%$ and $99 \%$ of the average declared cost respectively. In order to deeply analyze the incremental cost relationship of different green building stars, this paper analyzes the energy-saving single green technology, green technology classification and star level. Through the data, we can see that the information gain gap of green buildings with the same star level is very large, and the difference of gain cost reflected by different green technologies is not large, but the contribution rate of energysaving technology is greater. The gain cost of the energy-saving single index is shown in Table 1. It can be seen that there is no direct relationship between the two technologies, especially in the aspect of two-star green buildings where the gap is very obvious. The gain cost of renewable energy is lower than that of the energy-saving building technology.

Table 1. Gain cost of energy-saving single index.

\begin{tabular}{|c|c|c|}
\hline Green Building Star & $\begin{array}{l}\text { Building Energy Saving } \\
\left.\text { Technology (Yuan } / \mathrm{m}^{2}\right)\end{array}$ & $\begin{array}{c}\text { Renewable Resources } \\
\text { Utilization } \\
\text { Technology }\left(\text { Yuan } / \mathrm{m}^{2}\right)\end{array}$ \\
\hline A star & $1.58-49.57$ & $1.45-15.48$ \\
\hline Two stars & $13.19-223.30$ & $1.45-33.28$ \\
\hline Three stars & $0-170$ & $0-107.31$ \\
\hline
\end{tabular}

The incremental effect of green building refers to the direct and indirect effects in the whole life cycle of the building. The direct effect is usually measured by economic value, which refers to the money saved by the use of green technology and facilities in the process of building use. The indirect effect cannot be measured by economic value, but refers to the benefits to society and the environment. Therefore, only direct economic effects are considered. The calculation of the gain effect of energy-saving and energy utilization technology is divided into four parts. The enclosure structure with good thermal insulation performance can reduce the power consumption of HVAC and achieve a better economy. 
The calculation expression of the economic effect of energy-saving technology of enclosure structure is

$$
B_{W H}=\Delta Q_{W H} \times P_{D}=\left[\left(\frac{Q_{C}-Q_{H}^{\prime}}{E E R}\right)+\left(\frac{Q_{H}-Q_{H}^{\prime}}{C O P}\right)\right] \times P_{D}
$$

Among them, $\Delta Q_{W H}$ refers to the energy saved by the technology, the unit is $\mathrm{kW} / \mathrm{H}$, electricity price is expressed by $P_{D}$, the unit is yuan $/ \mathrm{kW} / \mathrm{H}, Q_{C}$ and $Q_{C}^{\prime}$ refer to annual summer cooling load consumption of basic building and green building, the unit is $\mathrm{kW} / \mathrm{H}$, $Q_{H}$ and $Q_{H}^{\prime}$ refer to annual winter heat load consumption of the basic building and green building, the unit is $\mathrm{kW} / \mathrm{H}, E E R$ and $C O P$ refer to energy efficiency ratio of basic building air conditioning refrigeration and heating, respectively. The calculation expression of the economic effect of air conditioning energy-saving technology is

$$
B_{K T}=\Delta Q_{K T} \times P_{D}=\left[\left(\frac{Q_{C}^{\prime}}{E E R}+\frac{Q_{H}^{\prime}}{C O P}\right)-\left(\frac{Q_{C}^{\prime}}{E E R^{\prime}}+\frac{Q_{H}^{\prime}}{C O P^{\prime}}\right)\right] \times P_{D}
$$

$\Delta Q_{K T}$ refers to the energy saved by the technology, $E E R^{\prime}$ and $C O P^{\prime}$ refer to the energy efficiency ratio of air conditioning refrigeration and heating of basic buildings respectively. HVAC energy-saving technology can greatly reduce energy consumption and electric energy. The economic effect of lighting and electrical energy-saving technology can be divided into two aspects. Green building can greatly reduce power consumption through intelligent lighting systems and energy-saving lamps, and its economic effect calculation expression is as follows

$$
B_{Z M}=\Delta Q_{Z M} \times P_{D}=\left(Q_{Z M}-Q_{Z M}^{\prime}\right) \times P_{D}
$$

The electric energy saved by using energy-saving lamps and intelligent lighting system is represented by $\Delta Q_{Z M}$, which refers to the annual power consumption of lighting system and energy-saving lamps used in basic buildings and green buildings respectively. The calculation formula of economic effect of installing energy-saving elevator in green building is

$$
B_{D T}=\Delta Q_{D T} \times P_{D}=\left[\frac{K_{1} \times K_{2} \times K_{3} \times H \times F \times P}{V \times 3600}+E\right] \times \alpha \times P_{D}
$$

$\Delta Q_{D T}$ refers to the energy saved by using energy-saving elevators. The energy-saving rate of energy-saving elevators is represented by $\alpha, E$ refers to the energy consumption of elevators in one year, $V$ refers to the speed of elevators, $F$ refers to the operation times of elevators in a year, the driving coefficient of the elevator system is $K_{1}$, the coefficients of adjustable speed drive system with AC voltage regulation and variable voltage and frequency are 1.6 and 1.0, respectively, and the average load coefficient of elevator car is $K_{3}$, The value is 0.35 , the average running distance coefficient of elevator is $K_{2}$, in which the value of two elevators is 1.0, the value of single and double elevators exceeding two floors is 0.5 , the value of three or more is $0.3, H$ is the maximum running distance of elevator, $P$ is the rated power of elevator. The economic effect of renewable energy utilization technology is expressed as follows

$$
B_{Z H}=\left(Q_{G F}+Q_{D Y}\right) \times P_{D}
$$

$Q_{G F}$ refers to the energy saved by using this technology. Therefore, the expression of the economic effect of energy conservation and comprehensive utilization technology is

$$
B_{J N}=B_{W H}+B_{K T}+B_{Z M}+B_{D T}
$$




\subsection{Economic Effect Evaluation Model of Green Energy Saving Building Based on Entropy Weight Method}

The ratio of gain effect to gain cost and the payback period of gain investment are selected as the evaluation index. Considering the influence of time cost, the dynamic investment return index is selected

$$
T_{C}=n-1+\frac{\left|\sum_{t=1}^{n-1} N P_{t}\right|}{N P_{n}}
$$

$n$ refers to the year with positive NPV, and $N P_{n}$ refers to the NPV of year $n$. The expression of the ratio of gain effect to gain cost is

$$
\Delta R=\frac{\sum_{k=0}^{n} \Delta Z_{t}(1+i)^{-t}}{\sum_{k=0}^{n} \Delta C_{t}(1+i)^{-t}}
$$

$\Delta \mathrm{Z}$ and $\Delta C_{t}$ refer to the economic income and additional expenditure of energy-saving technology in the $t$ year, $n$ refers to the use cycle of green buildings, $i$ refers to the social discount rate. When $\Delta R>1$, it shows that the economic effect of the scheme is good, when $\Delta R=1$, the scheme needs to be optimized, $\Delta R<1$ thinks that the scheme is meaningless. In this paper, the analytic hierarchy process (AHP) and entropy weight method are used to build the model. Analytic hierarchy process (AHP) sets the economic effect of green building as target layer D, and sets six kinds of building technology as D1, D2, D3, D4, d5 and D6 as six first-level indicators, and each criterion layer has different index layers. For example, D1 target layer contains four index layers, which are respectively represented by D11, D12, D13 and D14, with a total of 20 secondary indicators, and each secondary index will include $\Delta R$ and $T_{C}$. The hierarchical structure of AHP is shown in Figure 1.

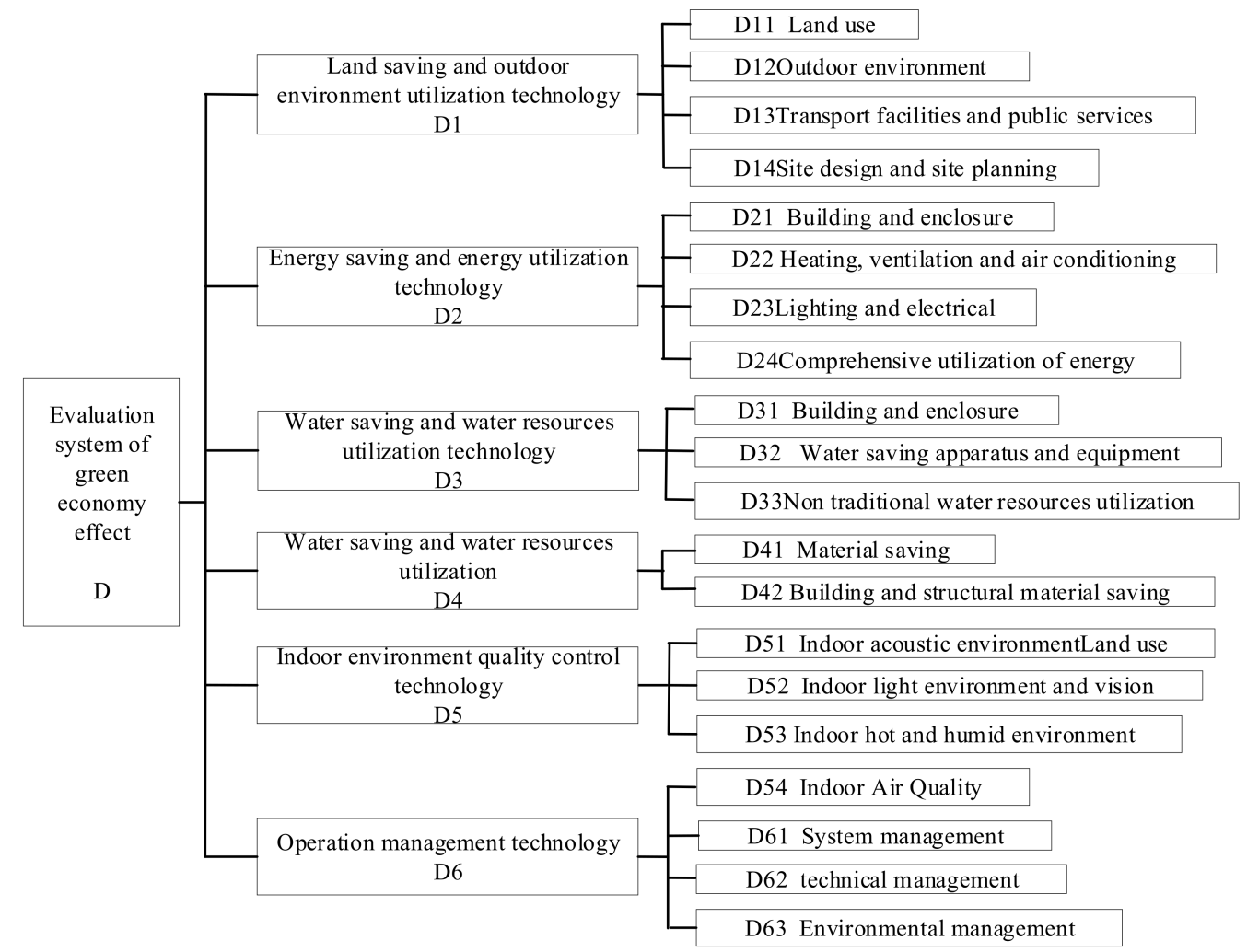

Figure 1. Schematic diagram of hierarchical transmission structure. 
Through the weight of the criterion level factors relative to the target factors, a pair comparison matrix is formed by using the relative importance of two factors. The maximum eigenvalue and corresponding eigenvector are calculated for each pair comparison matrix, and then consistency detection is carried out by consistency index, random consistency and consistency ratio. If the consistency detection meets the normal range, the normalized eigenvector can be used as the weight vector. If not, the pairwise comparison matrix needs to be rebuilt. The consistency test index refers to the consistency index, and its expression is

$$
C I=\frac{\lambda_{\max }-n}{n-1}
$$

where $\lambda_{\max }$ is the largest eigenvalue and $\mathrm{n}$ is the number of row vectors of the judgment matrix, $R I$ is the random consistency index, which is usually given by experimental experience, and $C R=\frac{C I}{R I}$ is the consistency ratio index; if $C R \leq 0.10$, the consistency of the judgment matrix is acceptable. The specific steps of objective weight assignment of entropy weight method are as follows. Firstly, $m$ experts are invited to evaluate $n$ indexes to get the original $\mathrm{R}$ matrix, which can be expressed as $R=\left(D_{i j}\right) n \times m$, and then normalize the $\mathrm{R}$ matrix to get the $P$ matrix. Secondly, according to the entropy principle, the entropy value $e_{i}$ of index I is calculated, the value range is $(0,1)$, and the expression is

$$
e_{i}=-k \sum_{j=1}^{n}\left(p_{i j} \ln p_{i j}\right)
$$

In the expression, $k=\ln \frac{1}{n}$. Furthermore, the difference coefficient of each index was calculated by Formula (12). The smaller the value, the greater the contribution rate of the index.

$$
d_{i}=1-e_{i}
$$

Finally, the entropy weight $w_{i}$ of index $\mathrm{I}$ is calculated by $d_{i} / \sum_{i=1}^{m} d_{i}$. Due to the advantages of the two algorithms in determining the weight, the combined weight can be obtained by a linear combination

$$
W=\alpha w_{i}^{a}+(1-a) w_{i}^{s}
$$

$w_{i}^{a}, w_{i}^{s}$ represents the weight obtained by AHP and entropy weight method respectively. In order to minimize the sum of squares of deviation between the two methods and the combined weight, it can be calculated that $\alpha$ is 0.5 . As the economic evaluation of green building is multi-index evaluation, including negative index, moderate index and positive index, in order to avoid the interference of different index orders and dimensions on the evaluation results, the dimensionless processing of $\Delta R, T_{C}$ two evaluation indexes is studied. The calculation model is that $\mathrm{x}$ is a positive index and negative index. When the original value $x_{j}$ of the $j$-th index is between the maximum possible value $x_{j \max }$ and the minimum possible value $x_{j \mathrm{~min}}$, the calculation model of the former is formula (14), otherwise the dimensionless quantized value $x_{j}(x)=0$ of the $j$-th index. The calculation model of the latter is Formula (15), otherwise $x_{j}(x)=0$.

$$
\begin{aligned}
& r_{j}(x)=\frac{1}{2}+\frac{1}{2} \sin \left[\frac{\pi}{x_{j \max }-x_{j \min }}\left(x_{j}-\frac{x_{j \max }-x_{j \mathrm{~min}}}{2}\right)\right] \\
& r_{j}(x)=\frac{1}{2}-\frac{1}{2} \sin \left[\frac{\pi}{x_{j \max }-x_{j \min }}\left(x_{j}-\frac{x_{j \max }-x_{j \mathrm{~min}}}{2}\right)\right]
\end{aligned}
$$

After calculation, the dimensionless quantitative matrix of each index in the criterion layer is obtained, and the final economic evaluation index is expressed as

$$
A=B D=\left[b_{1}, b_{2}, b_{3}, b_{4}, b_{5}, b_{6}\right]\left[d_{1}, d_{2}, d_{3}, d_{4}, d_{5}, d_{6}\right]^{T}
$$


$B$ refers to the weight of the criterion layer compared with the target layer. In this study, the economic effect of green technology is divided into five grades, namely, very good economic effect, good economic effect, good economic effect, general economic effect, and economic effect, which need to be improved. The scoring range is obtained according to the linear dimensionless quantitative method, and the economic effect evaluation grade scale is shown in Table 2.

Table 2. Grade scale of technical and economic evaluation of green building.

\begin{tabular}{ccc}
\hline $\begin{array}{c}\text { Technical and Economic Evaluation Level of } \\
\text { Green Building }\end{array}$ & Scoring Range & Star Rating \\
\hline The economic effect is very good & {$[0,0.2)$} & A star \\
\hline Good economic results & {$[0.2,0.4)$} & Two stars \\
\hline The economic effect is average & {$[0.4,0.6)$} & Three stars \\
\hline Certain economic effect & {$[0.6,0.8)$} & Four stars \\
\hline The economic effect needs to be improved & {$[0.8,1.0)$} & Five stars \\
\hline
\end{tabular}

\section{Experimental Design and Analysis}

This study uses the above formula to calculate the subjective weight and objective weight, respectively, and finally obtains the combination weight of all levels of indicators. The economic effect evaluation weight information of green building technology is shown in Figure 2, including the subjective weight, objective weight and combination weight of 20 secondary indicators. The combined weight results of six green building technologies on the economic effects of construction technology are

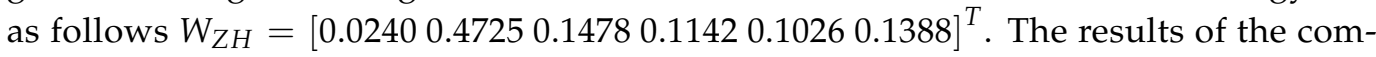
bined weights of the six criteria layers for their respective indicator layers are as follows $W_{\mathrm{ZH} 1}=\left[\begin{array}{lllll}0.1399 & 0.4975 & 0.1186 & 0.2439\end{array}\right]^{T}, W_{\mathrm{ZH} 2}=\left[\begin{array}{llll}0.1179 & 0.4224 & 0.2545 & 0.2052\end{array}\right]^{T}, W_{\mathrm{ZH} 3}=$ $\left[\begin{array}{llll}0.1678 & 0.5659 & 0.2663\end{array}\right]^{T}, W_{Z H 4}=\left[\begin{array}{llll}0.7725 & 0.2275\end{array}\right]^{T}, W_{Z H 5}=\left[\begin{array}{llll}0.1726 & 0.2955 & 0.2566 & 0.2753\end{array}\right]^{T}$, $W_{\mathrm{ZH6}}=\left[\begin{array}{lll}0.1530 & 0.5715 & 0.2755\end{array}\right]^{T}$.

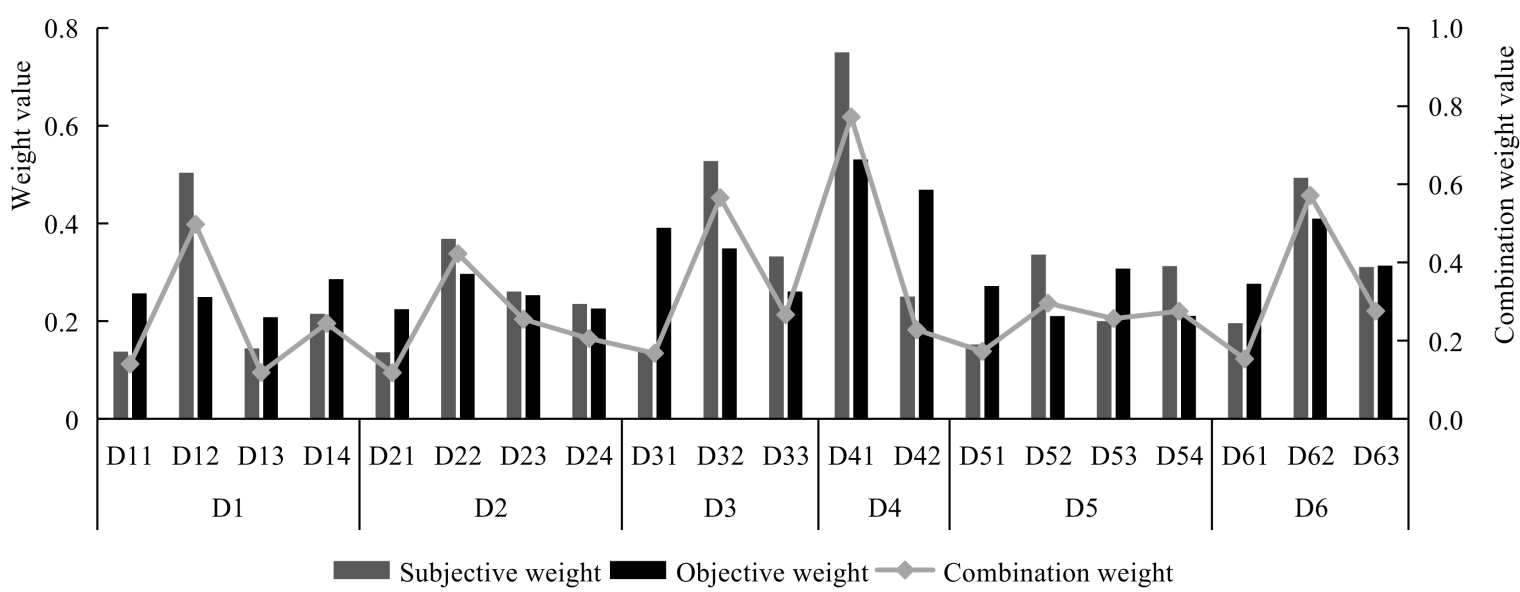

Figure 2. Weight information of economic effect evaluation of green building technology.

Based on market inquiry, network inquiry and other ways to determine the unit price of green building technology, the incremental cost of unit building area based on six evaluation indicators of 11 kinds of green building technology is $173.76 \mathrm{yuan} / \mathrm{m}^{2}$. In this paper, the incremental effects of the six green buildings are calculated, and the present value of the gain effect is obtained by using the present value calculation formula. The ratio of the present value to the total building area is the unit information increment. The calculation results are shown in Figure 3. Among them, land saving and environmental indicators are only vertical greening technology, the incremental economic effect and unit increment 
effect are 3070.984 yuan $/ \mathrm{m}^{2}$ and 3.695 yuan $/ \mathrm{m}^{2}$, respectively. The incremental economic effects of four green technologies in energy saving and resource utilization indicators are $44,256.75$ yuan, 1,015,924.2 yuan, 255,490 yuan, 32,871.57 yuan, and the unit increment effect is 53.253 yuan $/ \mathrm{m}^{2}, 855.47$ yuan $/ \mathrm{m}^{2}, 215.19$ yuan $/ \mathrm{m}^{2}, 122.98$ yuan $/ \mathrm{m}^{2}$. The total amount of incremental economic effect and unit increment effect of six evaluation indexes based on nine key green technologies are 1,472,113.3 yuan and 1501.99 yuan $/ \mathrm{m}^{2}$.
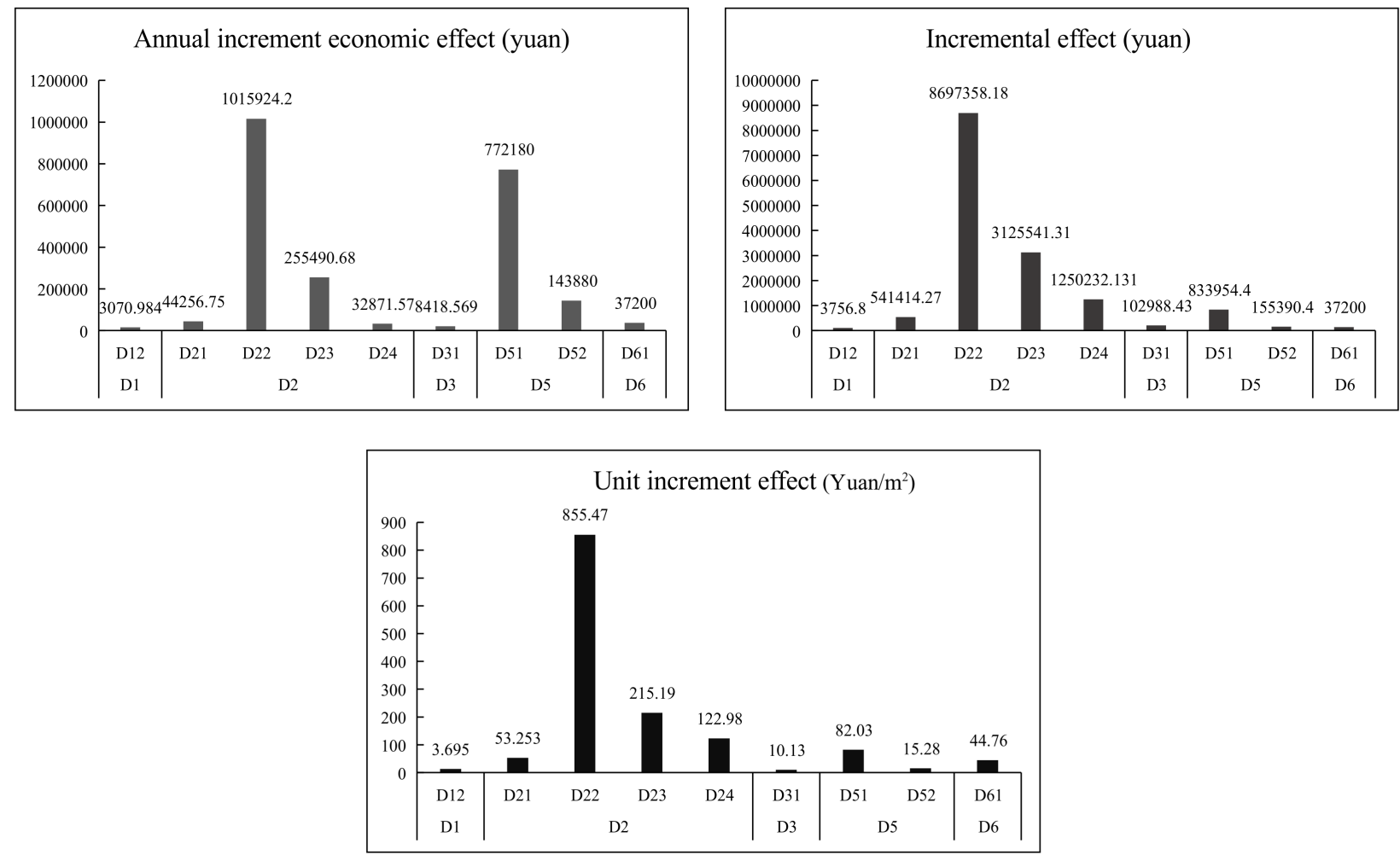

Figure 3. Green building energy-saving technology in incremental effect results.

As shown in Figure 4, in the indicators of energy conservation and resource utilization, the incremental economic benefit-cost ratios of the four green technologies are 2.56, 9.03, 5.01 and 9.99, respectively, and the incremental investment payback periods are 4.37 years, 2.02 years, 3.59 years and 5.18 years, respectively. In the economic indicators of material saving based on material saving and structure saving, the payback period of incremental investment is 0 , and the incremental economic benefit-cost ratio does not exist, because the present value of incremental cost is 0 . According to the calculation results of incremental cost and incremental effect, the economic evaluation indexes of various green building technologies are obtained by using the formula of incremental investment payback period and incremental economic effect cost rate. Compared with traditional building technology, the application of green building technology and related facilities and equipment can greatly reduce the consumption of building resources, so as to achieve the purpose of energy conservation and emission reduction. This method combines objective evaluation with subjective evaluation, which is the supplement of fair objective evaluation and expert evaluation. It makes full use of all basic information and ensures the scientific effectiveness of the comprehensive evaluation model.

Due to the space limitation, the research only shows the indexes that need dimensionless quantization, and the dimensionless quantitative indexes are shown in Figure 5a,b. It should be pointed out that the indicators not involved are not used in the project, or the economic effects generated are indirect economic effects. It can be seen that the energysaving and renewable resource utilization technologies have the most economic effects, while the material saving technology and indoor environmental quality control technology 
are not used or have indirect economic effects in the project, while the other two green technologies are involved, but the application is limited.
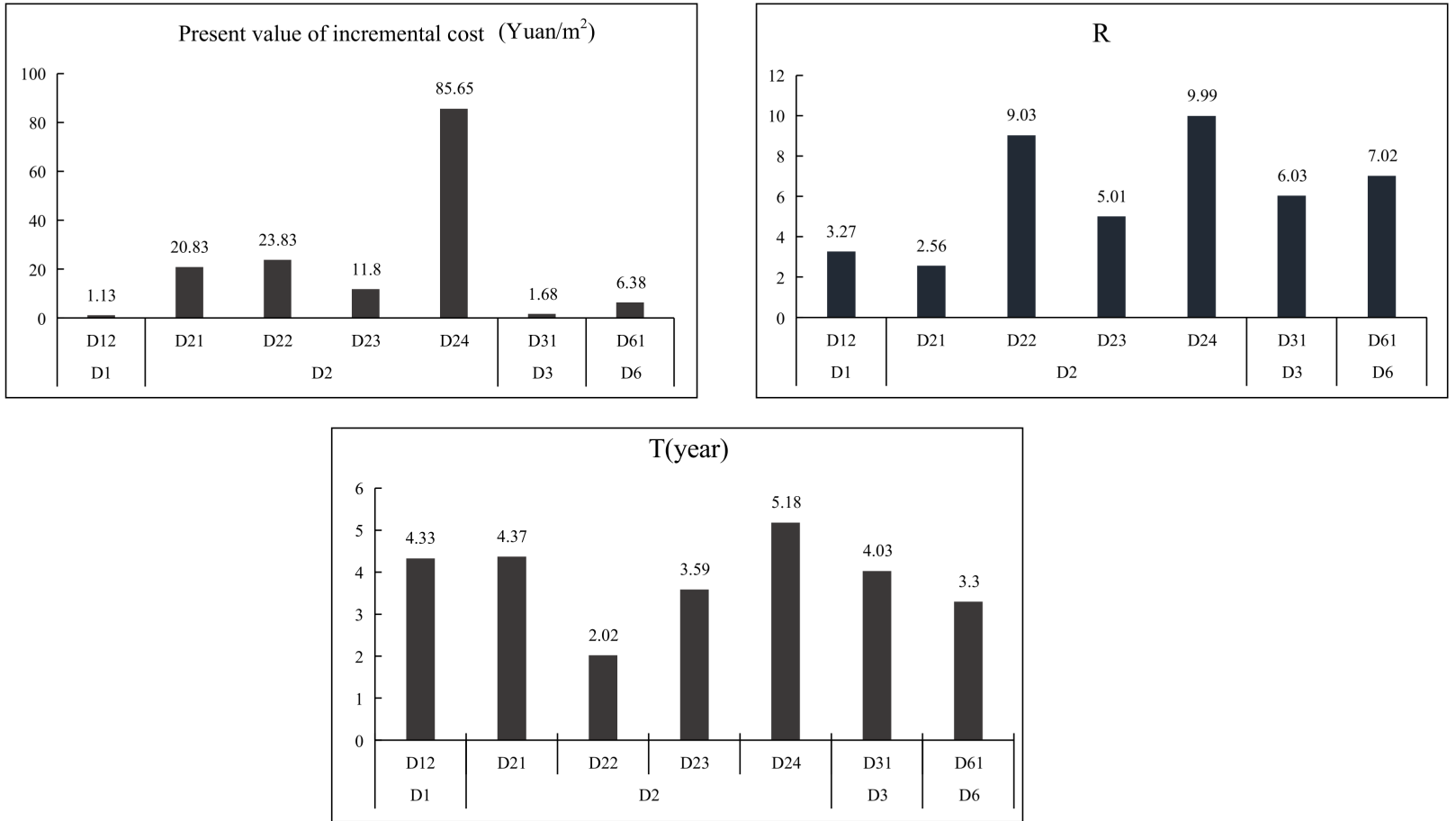

Figure 4. Evaluation index results of green building technology cost effect.

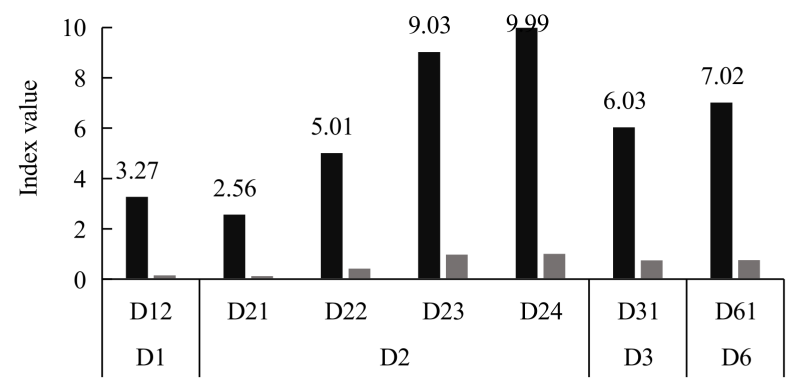

Index $\square$ Dimensionless quantitative index

(a)

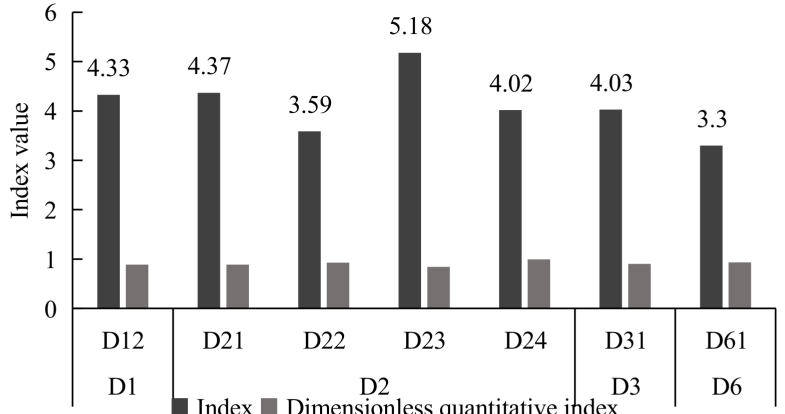

(b)

Figure 5. The results of dimensionless quantitative index of sum. (a) Dimensi onless quantitative index (0-10); (b) Dimensi onless quantitative index (0-6).

According to the above results, the score value of building energy-saving technology is finally obtained, and the results are shown in Figure 6. Figure 6a refers to the weight value and score value of the first level index, and (b) refers to the weight value of the second level index and the value after dimensionless quantitative treatment. It can be seen that the total evaluation score of the project is 0.404902 , because the economic effect of the construction technology used is general, and the star rating is three stars. The total score of energy-saving and renewable resources utilization index, land saving index, water-saving index and operation index was $0.02885362,0.240204,0.079443$ and 0.056719 , respectively. Energy-saving and renewable resources utilization indices scores were the highest, accounting for more than half of the total evaluation score. 


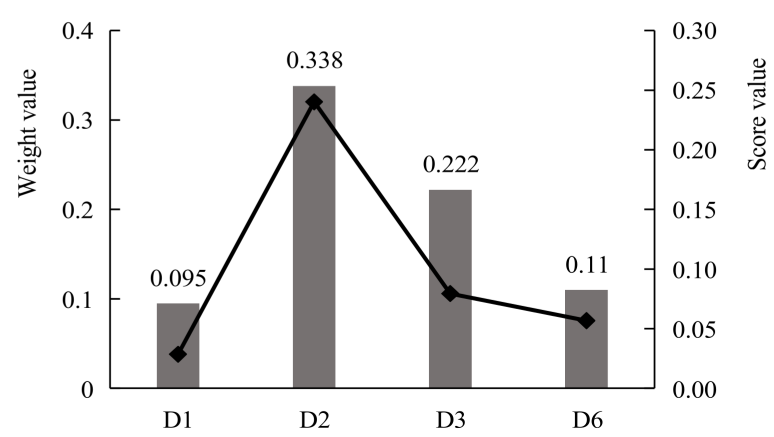

(a)

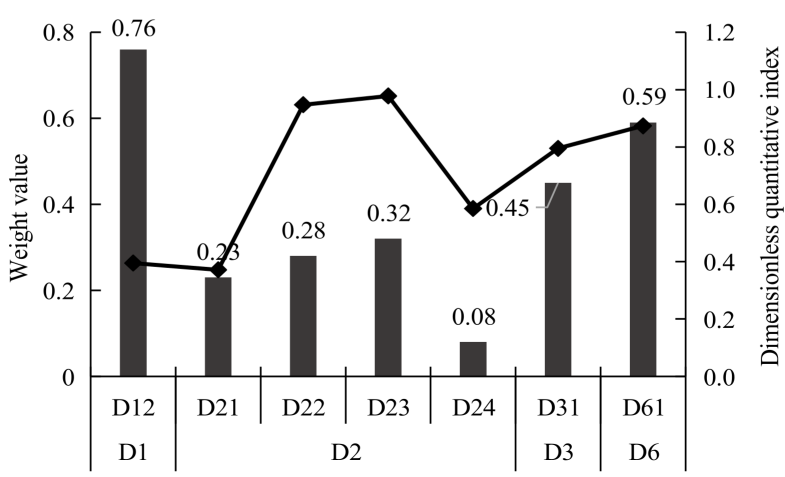

(b)

Figure 6. Score value of building energy-saving technology. (a) refers to the weight value and score value of the first level index, and (b) refers to the weight value of the second level index and the value after dimensionless quantitative treatment.

\section{Conclusions}

The application of green building technology and related facilities and equipment can greatly reduce the consumption of building resources so as to achieve the purpose of energy conservation and emission reduction. Based on the analysis of incremental cost and six kinds of incremental effects and the calculation formula, this study proposes an economic effect evaluation model of green building energy-saving technology based on the AHP and entropy weight method, determines the calculation formula of subjective and objective combination weight, and does not quantify the negative investment payback period and positive incremental economic effect ratio of 20 secondary indicators, calculating the economic effect score of green building. The empirical analysis shows that the incremental cost per unit building area of the six evaluation indicators is $173.76 \mathrm{yuan} / \mathrm{m}^{2}$, and the green energy-saving and renewable resource utilization technology is the largest contributor to the incremental cost. However, its incremental effect is also huge. The economic effect score of the energy conservation and renewable resources utilization index is 0.02885362 , accounting for more than half of the total evaluation score. The overall economy of the project is average. However, if the indirect economic effect is considered, the economic effect of the project will be better. The design of the green technology combination scheme of the actual green building project needs to adapt to local conditions, and adjust according to the gain effect and gain cost of water-saving, which is also the direction of the next research.

Author Contributions: Conceptualization, H.L. and X.S.; methodology, X.S.; software, F.D.; validation, X.S. and F.D.; formal analysis, H.L.; survey, X.S.; resources, X.S.; data collation, F.D.; preparation of the original draft, X.S.; review and editing, H.L. and F.D.; visualization, H.L.; Supervision, F.D.; Project management, H.L.; Funding: This article is not sponsored by any fund. All authors have read and agreed to the published version of the manuscript.

Funding: This research received no external funding.

Institutional Review Board Statement: For some reason, this study abandoned ethical review and approval, and the study did not involve the content of ethical review. Research that does not involve humans or animals.

Informed Consent Statement: All subjects involved in the study obtained informed consent, and the study did not involve human patients.

Data Availability Statement: The data used to support the findings of this study are included within the article.

Conflicts of Interest: The authors declare no conflict of interest. 


\section{References}

1. Sim, Y.L.; Putuhena, F.J. Green building technology initiatives to achieve construction quality and environmental sustainability in the construction industry in Malaysia. Manag. Environ. Qual. Int. J. 2015, 26, 233-249. [CrossRef]

2. Ekwe, E.B.; Abam, F.I. An Optimized Exergoeconomic Model for a Single-Shaft Modified GT-Plant with Intercooled Compression Based on PSO. Int. J. Eng. Technol. Sci. 2015, 3, 354-363.

3. Alimohammadi, N.; Maleki, B.; Shahriari, M.; Chitsaz, A. Effect of a care plan based on Roy adaptation model biological dimension on stroke patients' physiologic adaptation level. Iran. J. Nurs. Midwifery Res. 2015, 20, 275-281. [PubMed]

4. Ali, U.; Daud, N.M.; Nor, N.M.; Yusuf, M.A.; Yahya, M.A. Enhancement in green building technology including life cycle cost. Soc. Sci. 2019, 14, 148-154. [CrossRef]

5. Bhuyan, R.K.; Routara, B.C. Optimization the machining parameters by using VIKOR and Entropy Weight method during EDM process of Al-18\% SiCp Metal matrix composite. Decis. Sci. Lett. 2016, 5, 269-282. [CrossRef]

6. Zhou, T.; Zhou, Y. Fuzzy comprehensive evaluation of urban regeneration decision-making based on entropy weight method: Case study of yuzhong peninsula, China. J. Intell. Fuzzy Syst. 2015, 29, 2661-2668. [CrossRef]

7. Ji, Y.; Huang, G.H.; Sun, W. Risk assessment of hydropower stations through an integrated fuzzy entropy-weight multiple criteria decision making method: A case study of the Xiangxi River. Expert Syst. Appl. 2015, 42, 5380-5389. [CrossRef]

8. Delgado, A.; Romero, I. Environmental conflict analysis using an integrated grey clustering and entropy-weight method: A case study of a mining project in Peru. Environ. Model. Softw. 2016, 77, 108-121. [CrossRef]

9. Kritsanawonghong, S.; Gao, W.J.; Iamtrakul, P.; Kuroki, S. Evaluation of Green Building Technology by Introducing Micro Co-Generation System in Convenience Stores. Adv. Mater. Res. 2014, 935, 57-60. [CrossRef]

10. Lertpocasombut, K.; Sirimontree, S.; Witchayangkoon, B. Green Building Technology for Public Restroom Conceptual Design via SketchUp ${ }^{\circledR}$. Int. Trans. J. Eng. Manag. Appl. Sci. Technol. 2016, 7, 119-126.

11. Kumar, R.; Chakrabortty, S.; Pal, P. Membrane-integrated physico-chemical treatment of coke-oven wastewater: Transport modelling and economic evaluation. Environ. Sci. Pollut. Res. 2015, 22, 6010-6023. [CrossRef] [PubMed]

12. Bastardie, F.; Nielsen, J.R.; Eero, M.; Fuga, F.; Rindorf, A. Effects of changes in stock productivity and mixing on sustainable fishing and economic viability. ICES J. Mar. Sci. 2016, 74, 535-551. [CrossRef]

13. Verhaeghe, N.; De Greve, O.; Annemans, L. The potential health and economic effect of a Body Mass Index decrease in the overweight and obese population in Belgium. Public Health 2016, 134, 26-33. [CrossRef] [PubMed]

14. Liapis, K.J.; Politis, E.D. Disclosure of the Laffer economic effect in property valuations to fair value. J. Prop. Investig. Financ. 2018, 36, 305-318. [CrossRef]

15. Jara, H.X.; Schokkaert, E. Putting measures of individual well-being to use for ex-ante policy evaluation. J. Econ. Inequal. 2017, 15, 421-440. [CrossRef] 